\title{
On Ways to Connect Vocational Education with Regional Economic Development
}

\author{
Hongwei Zhang \\ Hubei Polytechnic Institute, Xiaogan 432000, China
}

Keywords: Vocational education. Regional Economy. Connection. Ways

\begin{abstract}
With further development of national economy and demands of intensified reform of educational system in China, inevitable connection between vocational education and industry has formed a consensus of people. The reason for this is that it is an important way to improve quality of vocational education and promote students' employment, acts as a core and key of vocational education reform and serves as a necessary condition under which regional economic development is driven. This thesis will explore related problems, for instance, ways to connect vocational education and regional economic development.
\end{abstract}

\section{The bottleneck restricting development of vocational education}

In recent years, higher vocational colleges have undertaken the social burden to cultivate skilled talent as the form of Chinese economy is changed from 'made in China' to 'created in China' and demands of the society for talent with vocational skills are obviously increased. The government's and all sectors' cognition about vocational education has been improved to a high stage in the process of economic reform and development, so they provide help for vocational education in the aspects of capital investment, policy support and openness of educational market resources. Just because of this, vocational education flourishes. However, there are many factors that restrict development of vocational education.

\section{A large financing gap exists in development of vocational education}

Since input into facilities used for practice and training in vocational education is high, capital investment needed by vocational education is high. However, the government's input into vocational education is limited for restriction of practical situations and traditional opinions. As a result, it is difficult to satisfy demands of future development of vocational education. This situation is reflected quite obviously at some local vocational colleges. According to the standard that RMB 8,000 government investment should be provided for each student each year, some colleges may only get half of the standard and even one third. Therefore, insufficient school-running funds have become an important bottleneck affecting stable and sustainable development of vocational education.

\section{A herd phenomenon exists in development of vocational education}

According to simple surveys and statistics, the author finds that there is a herd phenomenon in development of vocational education. In detail, independent colleges, key universities and even colleges ranking in the second batch in enrollment and the ones staying in the third batch in admission of universities run vocational education. This is a good thing because it drives vocational education to flourish and push industrial development. However, it is also a bad thing since it makes schools fight for source of students, funds and sites. As a result, resources of the whole society are lacked seriously and educational quality declines sharply. Here is an example about a province in Central China. Vocational colleges have emerged like bamboo shooting after a spring rain, appeared endlessly and exceeded people's demands largely in this province in recent years.

\section{Repeated construction exists in development of vocational education}

An overall plan must be made to do things well. There is no exception for the vocational education held by independent colleges, key universities, colleges ranking in the second batch in enrollment and even the ones staying in the third batch in admission of universities. However, the fact is that the phenomenon that there is repeated construction in development of vocational education is rather serious. Take a certain province for example as well. There are about 60 vocational colleges 
(excluding secondary vocational schools) with different scales in the province. However, only half of them have a school-running scale and level to some extent, while situations of the other half are self-evident. At the same time, repetition of major setup is rather serious. In addition, the number of sources of students is small, hardware is poor and quality is rather ordinary.

\section{Teaching quality of vocational education declines continuously}

Since Ministry of Education approved setup of the first batch of higher vocational education colleges in 1998 for the first time, it has been 15 years. During this period, higher vocational education develops rapidly. Up to now, the number of higher vocational schools in Chinas has exceeded 1,200, and the number of students at school has reached 13.30 million. Higher education has walked from elite education to mass education. In another word, it involves $80 \%$ of graduates from senior high school. In detail, a small number of such graduates enter universities for further study and most of them can attend and learn at vocational colleges. Considering vocational education only, the core problem does not lie in scale but involves that quality of educational teaching declines seriously at present. The reasons for this are rather complicated.

\section{How can we realize the connection between vocational education and regional economic development?}

Development of vocational education not only satisfies the wish that students in Grade 3 at senior high schools want to attend universities but also cultivates a large batch of skilled talent for the country and the society and promotes social and economic development. 'At present, importance of rapid development of higher vocational education has become a consensus of all people. Leaders at many places have realized that development of vocational education has not only acted as an important way to solve educational fairness problem but also served as obbligato and important support for regional economy.'

As economic development level is improved and emerging industry rises, requirements of all social fields, industries, departments and enterprises and public institutions for talent with high skills increasingly grow. Therefore, to respond actively, vocational education must find an entry point and blaze new trails in a pioneering spirit. The author deems that the entry point is the substantive connection between vocational education and industrial development.

'Planning connection' between vocational education and regional economic development

The connection between vocational education and regional economic development planning is a starting point and objective of survival and development of vocational education. Take this locality as an example. Xiaogan City directs at becoming a sub-center city in the urban circle of Wuhan. In the 12th five-year plan, the municipal Party committee and municipal government propose that it will focus on building 'three districts' and 'three cities' during the period. The 'three districts' include a development area where important and advanced manufacturing industry and high and new technology industry in the province gather, a key development zone for modern agriculture and processing industry for agricultural products and a chrematistic development district for business logistics and leisure tourism. The 'three cities' involve a large city with powerful regional driving force in the northeast of Hubei, a livable and leisure city with favorable ecological environment and a famous city representing filial piety culture of China. In addition, it will center on developing 6 industries including optoelectronics information, automobiles and parts, advanced equipment manufacture, bio-pharmaceuticals, textile and garment as well as paper for daily use, and building bases of modern service industry, such as commerce and trade, logistics, tourism, culture and finance radiating the northwest of the urban circle of Wuhan.

As local higher vocational colleges, they should take the responsibility to serve regional economic development. Thus, the connection between vocational education and regional economic development planning is mainly reflected by the following aspects.

Firstly, 'focus on industries to run majors'. Aiming at spirit in the '12th five-year plan' made by the municipal Party committee and the municipal government of Xiaogan City, local vocational colleges adjust specialty structure, focus on developing 6 industries including optoelectronics 
information, automobiles and parts, advanced equipment manufacture, bio-pharmaceuticals, textile and garment as well as paper for daily use and majors related to service industry, such as commerce and trade, logistics, tourism, culture and finance, to provide appropriate and useful skilled talent for local economic development.

Secondly, 'run majors well to promote industries'. Local vocational colleges should work hard to improve quality of educational teaching, especially in the aspects of cultivation of students' practical ability, comprehensive quality and professional ethics, and really reach the effect that 'enterprises can afford use of talent and retain talent' as well as parents and enterprises are satisfied.

Thirdly, local government sectors, enterprises and public institutions should connect with local vocational colleges, establish effective government-school-enterprise linkage mechanism, carry out comprehensive coordination and make overall planning for matters like full-time vocational education, skill training for enterprises' staff, training for transfer of rural labor and training for labor entering cities for work. At the same time, related sectors of governments at all levels should gradually establish, perfect and implement employment with certificates and employment access system that combines training course-completion certificates with job qualification certificates.

Fourthly, related sectors of government finance at all elves should guarantee all educational funds and training funds can be put in place feasibly.

It is necessary to enlarge input into infrastructure construction of vocational education, integrate sources of vocational education and enlarge scale of vocational education. In detail, boost construction of Xiaogan's vocation education group whose leading component is Hubei Polytechnic Institute and subjects include a batch of secondary vocational schools like Xiaogan Technical School and Xiaogan Bioengineering School and key enterprises, accelerate construction of Xiaogan Vocational Education Park and vocational education center of counties and the city, build a national brand of vocational education, make secondary vocational schools reach standards for provincial demonstration schools and the ones above the level, construct modern vocational education system with Xiaogan characteristics. In addition, it is necessary to enhance construction of practice and training bases and double-quality teacher and improve basic ability of vocational education. Besides, strengthen construction of brand majors like Numerical Control Mould, Electrician and Electronics, Construction Technology, Automobile Making, Bio-pharmaceuticals and Tourist Hotel Service, reinforce innovation of vocational education mechanism, perfect new management mechanisms of vocational education, such as level-to-level administration, local place-oriented principle, the government's overall planning and social participation, insist on regarding service as a purpose and treating employment as guidance, popularize the school-running mode with school-enterprise cooperation and learning-working combination and develop order cultivation energetically. Additionally, develop continuing education energetically, make internet remote education progress and build a learning society actively.

'Resource connection' between vocational education and industrial enterprises in the region

This kind of connection is mainly reflected by three aspects including manpower, financial resource and material resource.

Connection in the aspect of manpower. Industrial enterprises and vocational colleges have their unique human resource advantages and hold strong complementarity. First of all, teaching quality of vocational education depends on level of teaching staff. Secondly, employment standard and requirements of industrial enterprises are important bases on which schools formulate schemes about talent cultivation. Next, 'go global' and 'bring in' strategies are scientific methods for schools' teaching staff construction.

Connection in the aspect of financial resources. The situation that industrial enterprises run education is not anything new. In the past, this had nature of governmental behaviors to a large extent. However, manners and morals of the time change at present. In detail, enterprises are restructured and have an eye to the main chance, so they do not run education any more. The author deems that this is cognitional misunderstanding. In a sense, both economic benefit and social benefit brought by the situation that industrial enterprises run education are not lower than the ones resulted from operation of substantial economy. 
Money is not a problem for some Chinese enterprises, so they use spare money to do investment and financing or carry out 'movement of enclosures'. Why are enterprises unwilling to run education? A very important point lies in the government's policy orientation. The author thinks that the government may use methods, for instance, reducing or remitting taxes, to encourage enterprises to invest education. There are numerous similar cases in foreign countries and China.

Connection in the aspect of material resources. There are many material resources at enterprises, which can be used by vocational education, such as production and management sites and machinery equipment. All of these are just things needed by vocational education when they cultivate students' practical ability. When vocational colleges lack capitals, they do not vitalize such enterprise resources. The reason for this lies in how to realize a win-win situation of schools and enterprises, including cooperative mode and mechanism, people management and benefit distribution. Of course, schools are a largely passive part at this point.

\section{'Training connection' between vocational education and industrial enterprises}

Training about theoretical knowledge and practical skills of enterprises' employees is responsibilities and obligations of vocational education. Generally speaking, majors established by vocational colleges are the same or similar to requirements of training about theoretical knowledge and practical skills of enterprises' employees. Usually, a vocational college establishes at least over 20 majors and even more than 50 majors at most. Such majors involve financial accounting, logistics management, business management, vehicle maintenance, medical care, computer application, tourism and hotel, household management service, construction and decoration, financial and insurance, plantation and cultivation, garment making, food fresh keeping, legal service and office secretary etc., and nearly cover demands of all industrial enterprises for employees' knowledge and ability. This advantage cannot be replaced with any other department or unit.

\section{'Mechanism connection' between higher vocational education and training of enterprises' employees in the region}

After running schools for many years, vocational colleges have accumulated abundant school-running experience, forms, methods and approaches, which makes them have a unique position in work related to training of enterprises' employees.

Firstly, training forms can be diversified. Training for enterprises' employees should be carried out in the form that combines intensive teaching with on-site guidance according to such employees' work features, and classroom can be established on construction sites and in workshop. With respect to teaching time, off-job training and spare-time training can be combined. Except for holidays, rest days and eight hours, classes and lessons can be offered as long as there are demands. Considering length of schooling, several flexible forms can be taken, such as training, short-term training or ultra-short training etc.

Secondly, training objects may be layered. In another word, 'differential treatment in education' is carried out according to different training objects and layers. For most of corporate employees whose cultural level reaches junior high school or above, some systematic training in the aspect of technical jobs and standardized management and operation with some technical difficulty but not high requirements may be implemented to make corporate employees change from purely physical labor to physical and skilled type. For a few corporate employees with lower cultural level, training about technical work with low difficult and easy operation can be performed.

Thirdly, training content should be practical. Training should not be limited to teaching materials or break away from teaching materials but focus on highlighting key points and effectiveness all the time. In addition, training ought to explain the profound in simple terms, be popular and easy to understand, involve accidents and cases as well as answer questions and help employees overcome difficulty. Meanwhile, it is essential to pay attention to training corporate employees' physical emotion, legal knowledge, team spirit and safety awareness to lay a foundation for harmonious development of enterprises and individuals.

Fourthly, training and verification should be specific. Aiming at the situation that some industries require applicants should provided related certificates for employment, training schools issue graduation (course-completion) certificates or job qualification certificates to corporate employees 
with qualified performance by assessment. At the same time, vocational colleges cooperate with related departments and industrial associations to hold corporate employees' skill competition occasionally, identity levels of their skills and issue certificates. Only in this way can training be attractive and a triple-win situation among training subjects, training objects and employers be reflected.

'Resource connection' between higher vocational education and rural migrant workers' training in the region

School-running resources of vocational schools are relatively complete. They not only serve students at school but also may provide training service for rural migrant worker. Everything needed is ready at vocational college, such as teachers, teaching materials, classrooms, training rooms (bases), computer and internet, experimental articles, mechanical equipment and distance education etc. Thus, they can provide material support for training of corporate employees' training. Some vocational colleges are included in the list of bases for cultivation of short-supplied talent with application technology and demonstration bases for cultivation of national high-skilled talent by ministries and commissions, for instance, Ministry of Education. Support of the country and existing resource advantages of vocational colleges make corporate employees' training offered by vocational colleges even better.

Paying attention to country-oriented vocational education, improving farmers' vocational skills and transfer employment ability, enhancing corporate employees' transfer employment training and improving vocational skills and employment ability of farmers who go to cities for work are responsibilities and obligations that vocational colleges must spend much time to finish as well as essential elements by which local government drives regional economic development.

\section{References}

[1] Li Jianlin: Local Colleges Should Undertake Responsibilities for Regional Development. China Education Journal, 2013-10-16.

[2] Qian Guohua: On Connection between Major Construction of Vocational Education and Industrial Strategic Focus. Education and Career, 2012(18).

[3] Ma Shuchao: Combination of Learning and Working: Key Measures for Connection between Vocational Education and Employees, Vocational \& Technical Educational Forum, 2007(1).

[4] Planning for National Corporate Employee Training from 2003 to 2010 formulated by six ministries and commissions including Ministry of Agriculture, September 2003.

[5] Website of Ministry of Education of the People’s Republic of China: http://www.moe.edu.cn/ 